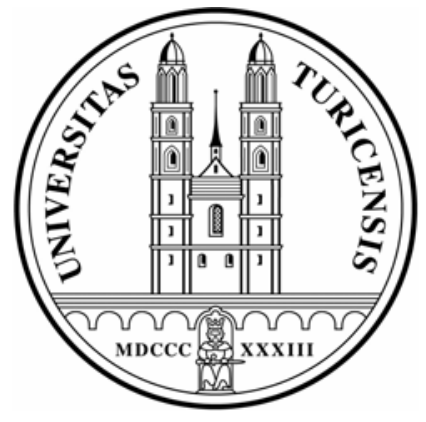

Institute for Empirical Research in Economics

University of Zurich

Working Paper Series

ISSN 1424-0459

Working Paper No. 316

The Home Bias and Capital Income Flows between

Countries and Regions

Michael J. Artis and Mathias Hoffmann

March 2007 


\title{
The Home Bias and Capital Income Flows between Countries and Regions ${ }^{1}$
}

\author{
Michael J. Artis ${ }^{2}$ \\ Mathias Hoffmann ${ }^{3}$
}

This version: March 2007

\footnotetext{
${ }^{1}$ We are grateful to the late Oved Yosha for many discussions that inspired the writing of this paper. We would also like to thank Bent Sørensen, Peter Pedroni and Jan Lemmen as well as seminar participants at Houston University, University of Zurich and the 2nd DG ECFIN research conference for their comments.

${ }^{2}$ Institute of Political and Economic Governance, University of Manchester, Williamson Building, Oxford Rd., Manchester M13 9PL, UK. E-Mail: michael.artis@manchester.ac.uk

${ }^{3}$ Corresponding author. Full address: Chair of International Trade and Finance, Institute for Empirical Research in Economics, University of Zurich, Zuerichbergstrasse 14, CH-8032 Zurich. E-Mail: mathias.hoffmann@iew.unizh.ch Earlier research on which this paper is partially based was funded by the Economic and Social Research Council in the framework of the 'Evolving Macroeconomy' programme (Grant \# L138251037). Hoffmann's work on this paper is part of the project 'The International Allocation of Risk' funded by the Deutsche Forschungsgemeinschaft in the framework of SFB 475.
} 


\begin{abstract}
This paper documents a marked increase in international consumption risk sharing throughout the recent globalization period. Unlike earlier studies that have found it difficult to document a consistent effect of financial globalization on international consumption comovements, we make use of the information implicit in the relative levels of consumption and output to measure long-run risk sharing among OECD countries and US federal states. We derive our empirical setup from a deliberately simplistic model in which countries can trade perpetual claims to each other's output (Shiller securities). Our framework allows us to distinguish between two channels of risk sharing: ex ante diversification that leads to income smoothing through capital income flows and ex-post consumption smoothing through savings and dissavings. The model successfully replicates the patterns of income and consumption smoothing observed in both U.S. state-level and international data. The increase in international consumption risk sharing is closely associated with the decline in international portfolio home bias. While capital income flows remain relatively limited as a channel of risk sharing at business cycle frequencies, we find that better international portfolio diversification has led to a considerable increase in capital income flows at medium and long horizons.
\end{abstract}

Keywords: Consumption Risk Sharing, International and regional business cycles, Capital flows, Home Bias, Non-stationary panel data

JEL classification: C23, E21, F36 


\section{Introduction}

Financial market integration should lead to better international consumption risk sharing. Our first objective in this paper is to show that consumption risk sharing among OECD countries has indeed increased considerably during the recent globalization period, i.e. in particular after 1990. Our second objective is to investigate to what extent improvements in international consumption risk sharing have been associated with increases in international factor income flows and whether these improvements can eventually be linked to the dramatic increase in international cross-holdings of financial assets that has been documented in the recent literature.

The extant literature on international risk sharing has found it difficult to document a consistent effect of financial globalization on consumption. In line with most of this literature we base our empirical analysis here on a key implication of complete financial markets: fluctuations in relative (i.e. idiosyncratic) marginal utility growth should be independent of idiosyncratic risk (as measured by relative output growth rates). Therefore, the coefficient of a regression of relative consumption growth on relative output growth should be zero. ${ }^{1}$ If financial markets are incomplete, the size of this coefficient can be directly interpreted as a measure of the deviation from the complete markets outcome. Generally, such risk sharing regressions have been estimated with data that has been rendered stationary through first differencing. One novelty of our approach is to use the information implicit in the levels of relative consumption and output by running (panel) risk sharing regressions in relative log levels rather than in relative growth rates. The level specification allows us to document longer-term trends in consumption risk sharing that other specifications, based on first differences of the data, have not been able to pick up. Based on our level specification, we document that consumption risk sharing has indeed increased considerably since 1990.

We motivate our econometric approach from a simple model that allows us to interpret the coefficient in the risk sharing regression as the share of the average country's or region's wealth held in claims to domestic output the coefficient is a measure of portfolio 'home bias'. Our framework, while consistent with virtually all theoretical models of consumption behaviour, is sufficiently simple to allow us to address the second objective of this paper: once we have estimated the degree of home bias based on consumption and output data, we can use the model to generate income data (defined as output

\footnotetext{
${ }^{1}$ Similar regressions were first proposed by Mace (1991), Cochrane (1991) and Townsend (1994) as tests of the null of market completeness. In the macroeconomic literature, they were popularized by Asdrubali, Sørensen and Yosha (1996), Crucini (1999) and others. For an excellent survey on home bias and consumption risk sharing see Lewis (1999).
} 
plus net capital income flows) that we then compare to real-world GNP and state level income data.

Our empirical analysis is based on two data sets: the first is an international (OECD) data set and ranges from 1960 to 2004, whereas the second is the data set for U.S. federal states employed in the seminal paper by Asdrubali, Sørensen and Yosha (1996). This data set ranges from 1960-90. Our findings can be summarized as follows:

The lack of international consumption risk sharing that is so widely documented in the literature is considerably less pronounced in what we refer to as the globalization period, i.e. after 1990. These improvements in international consumption risk sharing are explained mainly by increases in international capital income flows. Our model - estimated from consumption and output data alone - correctly predicts this growth in risk sharing through international income flows and it successfully replicates the patterns of consumption smoothing and income risk sharing among both U.S. federal states and OECD countries. In addition, we show that both phenomena the growth in international capital income flows and risk sharing - are driven by the explosion of international gross holdings of foreign assets over the last fifteen years.

Our results would seem to contradict a key stylized fact established by the recent literature on international risk sharing: From the seminal papers by Asdrubali, Sørensen and Yosha (1996) and Sørensen and Yosha (1998) we know that capital income flows derived from cross-holdings of claims to productive capital are a much more important channel of risk sharing among regions or federal states than among countries. Indeed, following Sørensen and Yosha (1998), a number of authors (Lane (2001) and Becker and Hoffmann (2006)) have shown that the fact that this channel is virtually absent in international data can account for virtually all of the lack of consumption risk sharing at the international level. While a number of studies using more recent data also discover a growth in risk sharing and in capital income flows, this increase is relatively modest and remains limited both relative to the growth in international asset gross holdings and to the increase in risk sharing we document here (See Sørensen, Yosha, Wu and Zu (2006) and Kose, Prasad and Terrones (2006) as well as the literature surveyed there).

We corroborate the tenor of the results of these studies and it would therefore seem surprising that capital income flows derived from gross-holdings of foreign assets are such an important source of risk sharing. The reason, why our results are so different is, again, that our level risk sharing regressions let us focus on the medium to longer term. At business cycle frequencies and as long as macroeconomic fluctuations are transitory it may not make a big difference for consumption allocations whether countries smooth their 
consumption through savings or dissavings or through capital income flows derived e.g. from equity (Baxter and Crucini (1995)). Furthermore, a recent literature (Lane and Milesi Ferretti (2003), Gourinchas and Rey (2006)) has started to emphasize the role of valuation effects for the dynamics of foreign asset positions. At short horizons, such valuation effects could in principle act as an insurance mechanism that provides an alternative to foreign capital income flows. For these reasons we argue that it is at the longer horizon where we should expect to see the impact of declining home bias on capital income flows most strongly and this is what we find in the data.

Recent contributions to which our paper is directly related are Lane and Milesi-Ferretti (2001, 2003) and Sørensen, Yosha, Wu and Zu (2006).

Lane and Milesi-Ferretti document the virtual explosion in international asset cross-holdings during the 1990s. We find that this phenomenon is a key driving force behind improvements in medium to long term risk sharing through capital income flows.

Sørensen et al. (2006) show that countries with higher shares of foreign assets in their net wealth tend to enjoy better income smoothing through higher international factor income flows. Therefore, the equity home bias and the lack of international consumption risk sharing appear as 'twin puzzles separated at birth'. Our paper maps this idea into a simple theoretical framework. This integrated framework puts us into the position to make predictions about the quantitative consistency of the decline in home bias, the growth in international capital income flows and the rise in risk sharing: over the period 1990-2004, average OECD asset gross holdings have grown from 170 to 470 percent of GDP. Over the same time, the fraction of longterm idiosyncratic output risk that gets shared internationally by the average OECD country has increased from less than 10 to more than 30 percent. Our model predicts that virtually all of this increase falls on capital income flows. We find overwhelming confirmation for this prediction in the data.

The remainder of this paper is structured as follows: in the next section we introduce our theoretical framework and use it to motivate the level risk sharing regression. In section three we present our data and obtain the country portfolio weights by estimating our level risk sharing regressions. In section four we relate the estimated portfolio weights to replicate the patterns of risk sharing, notably of capital income flows, both between countries and regions. We also show that the longer-term increase risk sharing through capital income flows that we find in international data is closely related to the growth in international gross asset positions. Section five summarizes and concludes. 


\section{Income flows, home bias, and consumption risk sharing: an integrated framework}

This section presents a general framework that allows us to study the link between consumption risk sharing, portfolio home bias and net capital income flows. In the first instance, we will use this framework to motivate an alternative way of measuring consumption risk sharing: our approach is based on panel regressions of relative log-levels of consumption on relative log levels of output. As we will argue, this approach is more likely to pick up the effects of financial globalization over time than are conventional approaches that have either used consumption correlations or regressions of consumption growth on output growth.

In a second step, we then ask if the pattern of interregional and international capital income flows is consistent with the predictions of the model and with the degree of international risk sharing that we have estimated.

Our framework nests virtually all current theories of consumption: the only assumption we make is that each period the representative inhabitant of country or region $k$ consumes a fraction $0<\mu_{t}^{k}<1$ of her income

$$
C_{t}^{k}=\mu_{t}^{k} I N C_{t}^{k}
$$

where $C$ and $I N C$ denote per capita values of consumption and income respectively. For example, this formulation is consistent with permanent income models, where $\mu_{t}^{k}$ captures the effect of discounting and uncertainty on consumption, given today's income. We will discuss the interpretation of $\mu_{t}^{k}$ in more detail below.

Now recall the definition of income from the national accounts: a country's income equals its output plus net claims to output produced in the rest of the world.

$$
I N C_{t}^{k}=Y_{t}^{k}+N F I_{t}^{k}
$$

where $N F I_{t}^{k}$ is net factor income from abroad, i.e. the country's net claims on flows of foreign output.

Recent work by Sørensen et al. (2006) demonstrates that the degree to which net factor income flows contribute to smoothing national income varies positively with the share of foreign assets in country wealth. They argue that the lack of international consumption risk sharing and the equity home bias are 'twin puzzles separated at birth'. We formalize this idea in our framework here by building on Crucini (1999). In order to link international income flows to the structure of countries' asset portfolios in a tractable manner, we assume that countries trade perpetual claims to their respective 
output streams. Such assets have first been suggested by Shiller (1993) and we therefore refer to them as Shiller securities. In our model, each country allocates its wealth between a claim to domestic assets and a world mutual fund of foreign Shiller securities. Since income constitutes the dividend from wealth, per capita income must be the weighted average of dividends paid on domestic and foreign assets. The dividends of Shiller securities are just foreign and domestic output, so that per capita income in country $k$ is

$$
I N C_{t}^{k}=\lambda Y_{t}^{*}+(1-\lambda) Y_{t}^{k}
$$

where $\lambda$ is the (ex ante value weighted) share of foreign assets in the country's wealth portfolio. Here, $Y_{t}^{k}$ denotes country $k$ per capita output and $Y_{t}^{*}$ is the average of per capita outputs across all countries. Note that under these assumptions, net factor income flows are given by

$$
N F I_{t}^{k}=Y_{t}^{k}-I N C_{t}^{k}=\lambda\left(Y_{t}^{*}-Y_{t}^{k}\right)
$$

which captures the idea that countries with higher portfolio shares of foreign assets will achieve more risk sharing through income smoothing, as discussed by Sørensen et al. (2006).

Perpetual claims to a country's entire output are not currently traded in world financial markets. But while our model is very stylized, we note that it is also quite general because existing assets - in particular equity - may at least in part allow countries and regions to replicate the pay-off structure of a portfolio of Shiller securities. Clearly, in frictionless markets, countries would want to diversify completely, which amounts to selling their national output to the world mutual fund. Hence, under complete diversification, we will have $\lambda=1$. But claims to a country's entire output would also comprise claims to labour income and other non-tradeable output components. Furthermore, we will expect that frictions in financial and goods markets will drive $\lambda$ away from unity. The parameter $\lambda$ is therefore a metric of how close observed income flows are to the income flows we would observe if countries or regions could completely diversify any idiosyncratic risk by investing all their wealth in a world portfolio of Shiller securities. We think of $\lambda$ as the effective degree of diversification of the average country and we refer to it as the 'Shiller portfolio weight' or as 'home bias': the parameter $\lambda$ tells us what share of a country's income is effectively derived from home and foreign sources and we turn to estimating $\lambda$ from the data. Plugging (3) into (1), we obtain

$$
C_{t}^{k}=\mu_{t}^{k} I N C_{t}^{k}=\mu_{t}^{k}\left[\lambda Y_{t}^{*}+(1-\lambda) Y_{t}^{k}\right]
$$

Note that this implies that countries will generally be able to decouple income and consumption through intertemporal substitution of consumption, 
e.g. through savings and dissavings. We can think of $\mu_{t}^{k}$ as capturing an array of country-specific effects such as the rates of return on the country's or region's wealth. For example, in the context of the permanent income hypothesis $(\mathrm{PIH})$, consumption should equal the permanent component of income defined as

$$
I N C_{t}^{k P}=\frac{r_{k}}{1+r_{k}} \mathbf{E}_{t}\left\{\sum_{l=0}^{\infty}\left[\frac{1}{1+r_{k}}\right]^{l}\left[I N C_{t+l}^{k}\right]\right\}
$$

where $r_{k}$ is the country's real interest rate and $\mathbf{E}_{t}$ is the expectations operator. Then, according to the $\mathrm{PIH}, C_{t}^{k}=I N C_{t}^{k P}$. Assume for expository purposes that income follows a stationary $\operatorname{AR}(1)$ with autoregressive coefficient $\rho$, $0<\rho<1$. Then

$$
C_{t}^{k}=\frac{r_{k}}{1+r_{k}-\rho} I N C_{t}^{k}
$$

so that in this simple case, $\mu_{t}^{k}=r_{k}\left(1+r_{k}-\rho\right)^{-1}$ is a country-specific constant reflecting the country's return on wealth and the persistence of its income process. Clearly, we could also let $r$ vary over time, so that we could think of variation in $\mu_{t}^{k}$ as reflecting time-variation in expected returns on country wealth.

In the next subsection, we are going to use equation (4) to develop a simple estimation equation for the portfolio weights $\lambda$ that is based on consumption and output data alone. The road map for the empirical part of the paper is then as follows: we first estimate values of $\lambda$. We then use these values to generate artificial income data according to (2) above. The properties of these artificial income data are then compared to actual GNP and personal state income data. Finally, we show that our measure of portfolio diversification, $\lambda$, has not only grown in international data but that this growth is actually closely linked to and quantitatively consistent with the decline in home bias that one sees in actual international portfolio positions of OECD countries.

\subsection{A risk sharing regression in levels}

We first re-write equation (4) by dividing by world income. For the link between world consumption and world income, we make an analogous assumption as for the home country, so that $C_{t}^{*}=\mu_{t}^{*} I N C_{t}^{*}$. Then using world per capita income as world per capita output, we obtain:

$$
\frac{C_{t}^{k}}{C_{t}^{*}}=\frac{\mu_{t}^{k}}{\mu_{t}^{*}}\left[\lambda+(1-\lambda) \frac{Y_{t}^{k}}{Y_{t}^{*}}\right]
$$


Equation (6) will not let us estimate $1-\lambda$ directly from a linear regression. We therefore base our estimation on a log-linear specification of (6). In addition, this offers the advantage that it is in keeping with most of the risk sharing regressions in the literature that are also largely based on loglinear specifications and keeping with this tradition facilitates highlighting parallels and differences in our approach. Secondly, specifications involving logarithmic levels rather than levels of macroeconomic variables are generally known to have normal residuals and would therefore - a priori - appear more robust.

We now make explicit the assumptions we make in log-linearizing (6). We apply logarithms on both sides of (6). Denoting $\phi_{t}^{k}=\log \mu_{t}^{k}-\log \mu_{t}^{*}$, we get

$$
\log \left(\frac{C_{t}^{k}}{C_{t}^{*}}\right)=\phi_{t}^{k}+\log \left[\lambda+(1-\lambda) \frac{Y_{t}^{k}}{Y_{t}^{*}}\right]
$$

Next, we expand the logarithmic term on the right hand side around $\frac{Y_{t}^{k P}}{Y_{t}^{* P}}=1$. This yields

$$
\begin{aligned}
\log \left[\lambda+(1-\lambda) \frac{Y_{t}^{k P}}{Y_{t}^{* P}}\right] & \approx \log [\lambda+(1-\lambda)]+\frac{(1-\lambda)}{\lambda+(1-\lambda)}\left[\frac{Y_{t}^{k}}{Y_{t}^{*}}-1\right] \\
& =(1-\lambda)\left[\frac{Y_{t}^{k}-Y_{t}^{*}}{Y_{t}^{*}}\right]
\end{aligned}
$$

Finally, approximating

$$
\log \left(\frac{Y_{t}^{k}}{Y_{t}^{*}}\right) \approx \frac{Y_{t}^{k}-Y_{t}^{*}}{Y_{t}^{*}}
$$

and plugging this expression back into the previous equation, we obtain the levels risk sharing regression that is the focus of the empirical analysis in this paper:

$$
\log \left(\frac{C_{t}^{k}}{C_{t}^{*}}\right)=\phi_{t}^{k}+(1-\lambda) \log \left(\frac{Y_{t}^{k}}{Y_{t}^{*}}\right)
$$

Having lower-case letters denote logarithms, we can write

$$
c_{t}^{k}-c_{t}^{*}=(1-\lambda)\left[y_{t}^{k}-y_{t}^{*}\right]+\phi_{t}^{k}
$$

This equation is reminiscent of the equations estimated in Mace (1991), Asdrubali, Sørensen and Yosha (1996), Cochrane (1991) or Crucini (1999). It relates relative consumption to relative output. Under full risk sharing, the coefficient on relative (permanent) output should be zero. The decisive 
difference vis-à-vis the earlier literature is that equation (9) relates relative log-levels whereas earlier implementations were formulated in differences.

In our derivation, we have assumed $\lambda$ to be the same across countries and in our empirical analysis we estimate (9) as a panel relation. This will allow us to obtain the degree of home bias $-(1-\lambda)$ - for the average country. Note that this setup, while quite similar in spirit to the literature that has estimated such regressions in first differences, estimating a non-stationary panel relation such as (9) allows for a high degree of unobserved heterogeneity across regions and countries through the time-varying, country-specific term $\phi_{t}^{k}{ }^{2}$ While $\phi$ can capture a wide array of different influences, the requirement that a country fulfill its intertemporal budget constraint imposes an important restriction: the process $\phi_{t}^{k}$ essentially reflects fluctuations in relative consumption-income ratios and intertemporal budget balance requires that, in the long run, a country's consumption will have to correspond to its income. While, even in the long-run, consumption and income may not literally be identical, e.g. because the country can systematically reap capital gains from foreign assets or because precautionary motives induce the country's residents to consume less than their actual income, we should still expect the long-run mean of $\mu_{t}^{k}$ and therefore also of $\phi_{t}^{k}$ to be constant, so that $\phi_{t}^{k}$ should be stationary. This stationarity of $\phi_{t}^{k}$ implies that (9) constitutes a panel cointegrating relationship. We discuss the econometric issues involved in the estimation of this relationship below.

We highlight the empirical advantages of our approach vis-à-vis the differenced versions of the risk sharing regression (9). Differenced specifications of the risk sharing regression or correlation-basesd measures of risk sharing (see e.g. the results in Artis and Hoffmann (2004) and Imbs (2006)) generally do not appear to pick up an increase in risk sharing over time. Heathcote and Perri (2004) even report that international consumption correlations have decreased for the U.S. Conversely, our results here clearly show an increase in risk sharing (a drop in the estimated coefficient) when we use the levels regression (9) and this increase in risk sharing can be associated with increased international cross-holdings of assets.

Why does the level regression pick up an increase in risk sharing that the differenced regression does not seem to register? The term $\phi_{t}^{k}$ is the wedge between changes in relative consumption and changes in relative income. According to standard consumption theory, fluctuations in the consumptionincome ratio should be a good indicator of future expected discount rates

\footnotetext{
${ }^{2}$ In our empirical implementation, we decompose $\phi_{t}^{k}=\phi_{k}+u_{t}^{k}$, where $\phi_{k}$ is a countryspecific fixed effect and $u_{t}^{k}$ is a residual. Clearly, besides $\phi_{k}$ additional deterministic but time varying country-specific terms (such as linear trends) could also be considered.
} 
or of future income changes. For example, in a permanent income model, if income changes are serially correlated, changes in $\phi_{t}^{k}$ will be correlated with changes in income and therefore also with $\Delta y-\Delta y^{*}$. Hence, the coefficient in the differenced regression will be a biased estimate of $(1-\lambda)$ and it will generally be a function of the particular nature of shocks. If the structure of cyclical shocks changes, the effect of financial integration on consumption correlations or the differenced risk sharing regression may get blurred. ${ }^{3}$ As is well-known, in a cointegrating regression such as (9), this simultaneity is much less of a problem because the joint non-stationary dynamics in relative output and consumption tends to dominate the stationary term $\phi_{t}^{k}$ in the estimation. Thus, we should expect the level risk sharing regression to pick up longer-term trends in risk sharing more robustly, whereas the outcome of the differenced regressions may also depend on what type of shocks tend to hit the economy. If the structure of shocks hitting a group of economies or the propagation mechanism to output is changing over time ${ }^{4}$, then the increase in risk sharing may not be picked up by differenced regressions. ${ }^{5}$

\section{Empirical Implementation}

\subsection{Data}

We apply our approach to two data sets: one for U.S. states and one for a group of 23 OECD countries. All data are annual.

The US-data set is the one also used by Asdrubali, Sørensen and Yosha ${ }^{6}$ and is based on gross-state product and income data from the Bureau of

\footnotetext{
${ }^{3}$ The quantitative-theoretical considerations in Heathcote and Perri (2004) strongly suggest that the nature of international shocks has changed since the beginning of the 1980s. In an earlier paper, (Artis and Hoffmann (2004)) we have explored the impact of this change on consumption correlations and the differenced regressions commonly used in the risk sharing literature.

${ }^{4}$ In fact, financial integration itself could be responsible for such changes. Imbs (2006) finds that the main reason why the quantity puzzle persists even between pairs of financially relatively integrated economies is that financial integration also increases business cycle correlations.

${ }^{5}$ We note that this is not tantamount to saying that an increase in risk sharing cannot possibly be teased out from the data using a differenced regression approach. For example, Sørensen et al. (2006) detect an increase in risk sharing once they relate a filtered sequence of cross-sectional estimates of the differenced regression to the growth in international portfolio holdings. However, our use of the levels regression tackles the problem in an arguably more direct way and allows a straightforward theoretical interpretation of the estimated coefficient.

${ }^{6}$ The data base is available at Oved Yosha's web page http://econ.tau.ac.il/research/riskshare/channels/channels.htm
} 
Economic Analysis (BEA). Since consumption data at the state level are not available, it is common practice ${ }^{7}$ to use retail sales data by state. These retail sales data are re-scaled by the share of retail sales in aggregate (US-wide) consumption to obtain measures of state level consumption data. All data are deflated by the US-wide consumption price index. The US-data range from 1960 to 1990.

Country-level data are from the Penn World Table, release 6.2 (PWT 6.12.) by Heston, Summers and Aten (2006) and range from 1960 to 2004. All data are in constant (2000) international prices. The countries included in our estimation are:

1. Canada, 2. the United States, 3. Japan, 4. Austria, 5. Belgium, 6. Denmark , 7. Finland, 8. France, 9. Germany (West), 10. Greece, 11. Iceland, 12. Ireland, 13. Italy, 14. Luxemburg, 15. Netherlands, 16. Norway, 17. Portugal, 18. Spain, 19. Sweden, 20. Switzerland, 21. United Kingdom, 22. Australia, 23. New Zealand.

Most of these countries are OECD countries and we will refer to them under this label. As regards the US, we follow the general practice in the US regional business cycle literature and include all states except Washington D.C.

We express all data in per capita terms. Rest of the World (RoW) aggregates are the US- or OECD-wide average per capita values. Population data are from the BEA and PWT respectively.

Over the sample period covered by our international data set, international financial markets have become increasingly liberalized. To take account of this change, we will report results obtained for two subperiods: the first covers the period 1960-1990, the second covers 1990-2004. The results we obtain from the first sub-period can be compared directly to others in the literature (the studies by Sørensen and Yosha (1998) and Crucini (1999) cover the same period), while the results from the second sub-period should provide insights into the effects of the dramatic increase in gross international asset positions that took place in particular in the 1990s (compare e.g. the data in Lane (2000), Lane and Milesi-Ferretti (2001, 2006) and Kraay, Loayza, Serven and Ventura (2000)).

\subsection{Estimating portfolio shares}

We now turn to estimating the Shiller portfolio weights based on the level risk sharing regression (9). In the light of our previous discussion, we treat

\footnotetext{
${ }^{7}$ Asdrubali, Sørensen and Yosha (1996), Hess and Shin (1998) and DelNegro(2002) all follow this approach.
} 
equation (9) as a cointegrating relationship. ${ }^{8}$

This relationship can, in principle, be estimated consistently by OLS. However, OLS may suffer from second-order bias due to potential simultaneity and serial correlation of the errors. Phillips and Moon (1999) therefore advocate a panel version of the fully modified least squares (FMLS) method. Since the FMLS estimator is semiparametric, it may, however, be imperfectly suited to relatively small samples. The panel dynamic OLS (PDOLS) estimator suggested by Mark and Sul (2003) may be preferable in this case. Also, Mark and Sul (2003) have forcefully argued for the dynamic panel OLS estimator on grounds of its computational simplicity. We conduct all our analyses here based on the panel OLS and the panel dynamic OLS estimator.

The panel dynamic OLS estimator accounts for serial correlation and potential simultaneity by including leads and lags of the differences of the right hand side variables. We experimented with various leads and lags and found our results to be very robust across specifications. All results were also very similar to those obtained from plain panel OLS estimates. The PDOLS parameter estimates in table 1 are based on one lead and lag for each country which we found sufficient to capture serial dependence in our annual data. To ensure that we can really treat (9) as a panel cointegrating relation, we perform Pedroni's (2004) group mean test for panel cointegration on the residuals of the country-wise PDOLS-regressions. These tests strongly suggests to reject the null of no cointegration in all samples and subperiods. They are reported as memorandum items at the bottom of table 1 .

In our estimation, we assume that the relative consumption-income ratio $\phi_{t}^{k}$ can be decomposed into a common-time-specific component $\tau_{t}$, a countryor region-specific fixed effect $\phi_{k}$ and into a country-specific mean zero residual process $u_{t}^{k}$ so that

$$
\phi_{t}^{k}=\tau_{t}+\phi_{k}+u_{t}^{k}
$$

The modelling of the term $\phi_{t}^{k}$ and in particular the treatment of the region- or country-specific fixed effect $\phi_{k}$ affects the interpretation of the estimated coefficients as measures of risk sharing and international diversification: the pooled estimate, which does not control for the fixed effect $\phi_{k}$, emphasizes the between-dimension of the data, similar to a between estimator which would eliminate all the within-country or region variation in $\phi_{t}^{k}$.

\footnotetext{
${ }^{8}$ Whether or not (9) constitutes a cointegrating relationship is without consequence for the point estimates of $(1-\lambda)$. As Phillips and Moon (1999) note, the coefficient of a non-stationary panel regression is meaningful even if there is no cointegration between the variables. The cointegration tests we report below do, however, support the view that (9) is a cointegrating relation.
} 
This tells us about the amount of risk sharing we would see if the countryspecific (relative) consumption-income ratios $\phi_{t}^{k}$ are close to their respective long-run means, so that - after income diversification - there is no further consumption smoothing out of current income. In the model above, in which we focus on the role of capital income flows for risk sharing, this is exactly what we aim to capture. We therefore associate the coefficient from the pooled regression with portfolio home bias and use it as our long-run risk sharing measure $1-\lambda$.

Conversely, the fixed effect estimate, that we denote with $\beta_{U}$, accentuates the impact of of departures of relative consumption-income ratios from their long-run mean. ${ }^{9}$ As we argue below, the cross-sectional covariance of $u_{t}^{k}$ with relative output growth, $\Delta y_{t}^{k}-\Delta y_{t}^{*}$, is a measure of the contribution of intertemporal consumption smoothing to risk sharing. We do not expect fluctuations in the consumption-income ratio to contribute to risk sharing in the very long-run, though. We therefore interpret $\beta_{U}$ as a measure of risk sharing at medium horizons, given the long-run portfolio home bias captured by $1-\lambda$.

We present the results from level risk sharing regression with and without country- or region fixed effects in table $1 .{ }^{10}$ Our findings carry a clear message: For US federal states, we find a home bias of around 50 percent, almost irrespective of whether we control for fixed effects or not. In international data, not controlling for fixed effects, we detect a home bias of over 90 percent in the 1960-90 period. For the later (i.e. the globalization) period, estimates of $(1-\lambda)$ are around 0.75 . This is considerably lower than in the 1960-90 period and the difference does appear to be significant. Once we control for country-heterogeneity by removing fixed effects, the increase in international risk sharing in the post-1990 period comes out even more strongly: for the $1960-90$ period we now find virtually no risk sharing $\left(\beta_{U}=0.98\right)$, whereas for the globalization period the corresponding value is around $\beta_{U}=0.65$. Note that the choice of estimation method (OLS vs. PDOLS) has virtually no effect on the results. ${ }^{11}$

\footnotetext{
${ }^{9}$ The fixed effect panel OLS estimator can be written as the time average of the crosssectional regressions of the previously demeaned variables (see e.g. Asdrubali, Sørensen and Yosha (1996)).

${ }^{10}$ In both cases, like in all panel regressions reported in the remainder of the paper, we control for time-fixed effects.

${ }^{11}$ This result is informative about the empirical relevance of theoretical scenarios in which consumption and output are incidentally correlated for reasons that are unrelated to financial markt incompleteness, for example, due to preferences that are non-separable in consumption and leisure as in Backus, Kehoe and Kydland (1992). The fact that we do not find major differences between the PDOLS - which implicitly controls for this incidental correlation - and the panel OLS estimates supports the notion that such non-separabilities
} 
The estimates in table 1 suggest that there is a lack of risk sharing in international data in both subperiods, but even at the regional level we find that U.S. citizens own a disproportionate share of the claims to output of the federal state in which they live - arond 50 percent of regional wealth is held in assets in the own region. This result provides a perspective on the relative size of intra- and international home bias: by measuring the effective degree of financial integration, we also take account of those components of a nation's or region's output risk that are not traded in financial markets: the equity of small firms or companies is most likely not traded across countries or regions nor are claims to the labour share of national or regional outputs. Our estimates seem to reflect this. Against this background, our estimate in table 1 of the increase in international portfolio diversification during the $1990 \mathrm{~s}-\mathrm{a}$ drop of $1-\lambda$ from 0.91 to 0.74 when no country-fixed effects are controlled for - amounts to a dramatic increase in international risk sharing: if our empirical measure of home bias among U.S. states $(\sim 0.5)$ is taken as a benchmark, then around 40 percent $((0.91-0.75) /(0.91-0.47)=0.17 / 0.43 \approx 0.4)$ of the international home bias (relative to regional home bias) has vanished in the years after 1990. This suggests that the increase in risk sharing in international data is not only statistically significant but also economically important. For the sample period we have examined here, i.e. from the late 1980 s or early 1990 s to 2004 , researchers who have examined international portfolio holdings directly (Lane (2000), Lane and Milesi-Ferretti (2001), Kraay et al. (2000)) report a considerable growth in the gross foreign asset positions of OECD countries. In the next section, we provide empirical evidence that better international portfolio diversification and the increase in international consumption risk sharing are closely related.

\section{Patterns of risk sharing and international asset positions}

Our theoretical framework allows an integrated treatment of consumption risk sharing and portfolio home bias. It also permits us to explore to what extent international asset positions help to share risk through international income flows. In this section, we now tie our abstract measure of home bias, $1-\lambda$, to evidence on actual portfolio holdings and on international capital income flows. First, in subsection 4.1 we show that our estimates of $\lambda$

are not likely to have an important effect on risk sharing regressions. This is in line with Backus, Kehoe and Kydland's own conclusion that the non-separability between consumption and leisure cannot quantitatively resolve the consumption correlation puzzle. 
are able to reproduce the patterns of capital income flows and intertemporal consumption smoothing as we observe them in both U.S. as well as in international data: capital income flows are the predominant channel of long-run risk sharing in U.S. data, and at the longer horizon on which we focus in this paper, they also explain the rise of risk sharing in international data. Secondly, section 4.2 demonstrates that the increase in $\lambda$ and the associated growth in international capital income flows are closely linked to the internationalisation of industrialised countries' asset portfolios as it has been documented in the recent literature.

\subsection{Channels of risk sharing}

Our theoretical framework nests two channels of risk sharing. The first is the one our discussions have been focussing on so far: capital income flows, that we associated with the wedge between a country's or region's output, may help a country to smooth its income. Building an Asdrubali, Sorensen and Yosha (1996), we measure the importance of this channel through regressions of the form

$$
\left[y_{t}^{k}-y_{t}^{*}\right]-\left[i n c_{t}^{k}-i n c_{t}^{*}\right]=\tau_{k}^{K}+\theta_{k}^{K}+\beta_{K}\left[y_{t}^{k}-y_{t}^{*}\right]+v_{t}^{K}
$$

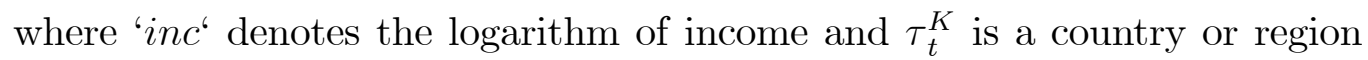
fixed effect. We think of international or interregional capital income flows as being derived from ex ante diversification of countries' or regions' portfolios.In our model this ex ante diversification amounts to the choice of the international portfolio weight $\lambda$ and if our model is in line with the data, we should therefore have $\beta_{K}=\lambda$. We call the channel the capital income flow, income smoothing or ex ante channel.

Secondly, countries or regions can further smooth consumption relative to income through intertemporal asset trade. Variation in the consumptionincome ratio ${ }^{12}$ captures to what extent a country or region manages to decouple its consumption. In our model, this is represented through time-variation in $\phi_{t}^{k}$. We refer to this second channel as the ex post or intertemporal channel or as consumption smoothing. We measure its contribution to risk sharing through regressions of the form

$$
\left[i n c_{t}^{k}-i n c_{t}^{*}\right]-\left[c_{t}^{k}-c_{t}^{*}\right]=\tau_{t}^{C}+\theta_{k}^{C}+\beta_{C}\left[y_{t}^{k}-y_{t}^{*}\right]+v_{t}^{C}
$$

Both the ex ante and ex post channels together account for the entirety of consumption risk sharing, so that

\footnotetext{
${ }^{12}$ Note that the (relative) consumption-income ratio corresponds to $\phi_{t}^{k}$ in (1) above
} 


$$
\beta_{K}+\beta_{C}=1-\beta_{U}
$$

and $\beta_{U}$ is the unsmoothed share of idiosyncratic risk, which can be obtained from the regression

$$
\left[c_{t}^{k}-c_{t}^{*}\right]=\tau_{t}^{U}+\theta_{k}^{U}+\beta_{U}\left[y_{t}^{k}-y_{t}^{*}\right]+v_{t}^{U}
$$

which is exactly the fixed effect level risk sharing regression that we have estimated in the previous section.

We call a particular combination of $\beta_{K}$ and $\beta_{C}$ a pattern of risk sharing. It is apparent that, while the total extent of risk sharing $1-\beta_{U}$ does not depend on income, the dynamics of income flows is key for the pattern of risk sharing: if there is no ex ante diversification of a country's or region's asset portfolio, we would expect income and output to be the same and $\beta_{K}=0$. Hence, any risk sharing would only occur ex post as consumption smoothing. Conversely, the same amount of overall risk sharing $1-\beta_{U}$ could be achieved ex ante through income flows alone, with consumption equalling income.

Thus, given $\beta_{U}$, the dynamics of income determines the pattern of risk sharing. Since, our model predicts that income is

$$
I N C_{t}^{k}=\lambda Y_{t}^{*}+(1-\lambda) Y_{t}^{k}
$$

the values of $\beta_{K}$ and $\beta_{C}$ depend directly on $\lambda$.

Using our estimate of $\lambda$, we generate artificial income data according to (12), based on actual values of GDP for $Y^{*}$ and $Y^{k}$. We then compare predicted income to actual GNP and state-leve income. Specifically, we estimate the panel equations (10) and (11) using real-world data for $y$ and $c$, but once based on actual income data and a second time using our artificial income data. In this way we check to what extent our model can replicate the pattern of risk sharing that we see in the data. We emphasize that this exercise imposes a strong but quite natural test on our model because $\lambda$ has been estimated from consumption and output data alone, without ever making use of income data.

For the U.S., the real world income data we use for this exercise is statelevel personal income. In international data, we measure income through gross national product (GNP). The Penn World Tables contain GNP only after 1970. We therefore limit our analysis of international data from now on to the post-1970 period. This does not affect the interpretation of our results since our estimates of $1-\lambda$ for the 1970-90 period are virtually identical to those obtained for the 1960-90 period.

For the generation of the artificial income data, we use a value for $1-\lambda$ of 0.48 for the United States. For the OECD countries, we set $1-\lambda$ to 0.91 in the 
1970-90 period and to 0.74 in the period 1990-2004. These values correspond to our estimates of $(1-\lambda)$ in table 1 , based on the PDOLS procedure in the model without fixed effects. At the bottom of table 2, we report the average across countries and regions of the correlations between artificial and actual idiosyncratic income growth rates. For the average U.S. state the correlation between actual and fitted income growth is 0.77 . At the international level, the model performs even better: here, it generates an average correlation of 0.94 in the $1970-90$ period and of 0.85 in 1990-2004.

We estimate equations (10) and (11) using panel dynamic OLS with one lead and lag, controlling for fixed effects and for common time-specific variation. The upper panel in table 2 reports the results based on both predicted and actual income data.

For the U.S., the predicted pattern of risk sharing is almost identical to that found in the data. In addition - very much as our model would predict - the values of $\beta_{K}$ and $\lambda$ are virtually the same. The estimates clearly suggest that most risk sharing in the U.S. takes place through capital income flows. While there is some consumption smoothing ex post, this appears overall insignificant. This confirms our previous expectation that - to the least in the longer term as it is emphasized by our theoretical and empirical framework - better risk sharing will have to be associated with larger capital income flows. To the extent that (relative) consumption-income ratios appear stationary in the data and to the extent that they are stationary in theory as, for example, in a permanent-income model - insurance against permanent shocks is possible only through ex ante diversification, not through ex post smoothing.

The same feature may explain why we find virtually no (long-run) risk sharing in international data in the pre-1990 period: the ex post channel is virtually inactive in the longer term, but so is the ex ante channel.

Though our model would somewhat overpredict the amount of ex ante risk sharing in the $70-90$ period (the predicted $\beta_{K}$ is 0.08 vs. 0.01 in the data), it remains true that the overall pattern of risk sharing is very much in line with what our model would predict: these are the results for the period before the huge internationalisation of asset ownership and we would expect that the huge portfolio home bias that prevailed at that time would be reflected in low capital income flows.

The picture changes completely once we turn to the globalization period: now there is a considerable amount of risk sharing in international data, roundabout one quarter to 30 percent of idiosyncratic output risk gets shared ex ante. There is also a moderate increase in ex post consumption smoothing. But this effect is much more subdued and the ex post channel appears only marginally significant. Again, the regressions based on predicted income get 
very close to the real-world pattern of risk sharing.

The results here would seem to stand in contrast to an important literature that has shown that international risk sharing is lower than in U.S. data mainly because international capital income flows do not contribute to risk sharing (Sørensen and Yosha (1998), Becker and Hoffmann (2006)). Lane (2001) concludes that international investment income flows have practically no bearing on risk sharing internationally. These analyses have typically focused on business cycle frequencies of the data by looking at versions of the regressions (10) and (11) that are formulated in first differences. In the middle panel of table 3 we estimate such differenced regressions, again for actual and predicted income flows.

The regressions based on actual income clearly corroborate the findings in the studies referenced above: The lack of international consumption risk sharing frequently is mainly a lack of ex ante income smoothing: for the 196090 period we find roundabout 40 percent income smoothing for the U.S. and virtually none in international data. We find a small rise in international consumption risk sharing in the 1990-2004 period, with $\beta_{K}+\beta_{C}$ increasing from 0.27 to 0.33 . But this difference seems tiny and appears insignificant. Furthermore, even in the globalization period, only a small share of an increase would be explained by capital income flows; $\beta_{K}$ increases from 0.03 to 0.06 and, again, the increase is insignificant.

We are primarily concerned with the long-term relation between income flows, home bias and consumption risk sharing. Still, it is interesting to see that our model is able to match the business cycle frequency patterns of risk sharing among U.S. federal states . It does, however, predict too much income smoothing and too little consumption smoothing ex post in international data. Given the focus of the paper, we do not explore this finding in any depth. Valuation effects on foreign asset positions as they have been emphasized by a recent literature could however provide an explanation: in the short to medium-term, valuation effects may allow a country to smooth consumption through the realization of capital gains rather than through capital income. Since the realization of capital gains amounts to a sale of foreign assets and therefore works through the ex post channel our model would - for a given average stock of foreign assets - tend to overpredict income smoothing and underpredict consumption smoothing, exactly as we observe it here. According to the results in Gourinchas and Rey (2006), valuation effects are mainly driven by exchange rate changes, which could also explain why we match the pattern of risk sharing at the business cycle frequency in U.S. data but not in international data. We explore the role of valuation effects for international risk sharing at the business cycle frequency in separate, still ongoing work. At the longer horizon, however, quite in keeping 
with the results reported e.g. by Gourinchas and Rey (2006), one would expect these valuation effects to play a rather minor role. Our results not only lend further support to this view. They also provide further justification for our approach here: to look for the link between consumption risk-sharing, capital income flows and home bias in the lower frequencies of the data.

We sum up our findings in this subsection as follows: In spite of its simplicity, we find that our model does a very good job in replicating the longer term patterns of risk sharing both among U.S. federal states and in international data. At medium to longer horizons, the increase in international risk sharing is associated with an increase in international capital income flows. We now show that both phenomena have a common explanation: the decline in international portfolio home bias.

\subsection{The increase in international risk sharing and the growth in gross international asset positions}

In this subsection, we show that the decline in our home bias measure $1-\lambda$ is closely linked to the internationalisation of asset ownership. As our measure of international portfolio diversification we use gross asset positions, the sum of assets and liabilities, relative to GDP. This choice is based on some a priori theoretical and empirical considerations. First, Obstfeld (2004) distinguishes between two motives for asset trade: intertemporal or development asset trade, which is reflected in net investment positions and diversification asset trade, which he associates with gross asset positions. Our interest in this paper is clearly in the risk sharing or diversfication aspect of asset trade. Secondly, measuring home bias through gross asset positions is consistent with our model in which the average country swaps a share $\lambda$ of claims to its own output for a share $\lambda$ of claims to world average output. Hence, $\lambda$ is a measure of the cross-sectional average of country's gross asset positions. Finally, the focus on gross asset positions can also be justified at an empirical level: Lane and Milesi-Ferretti (2003) note that there has been a virtual explosion in the gross-holdings of assets whereas net positions have remained quite stable. In identifying a cause for the huge increase in risk sharing, one may therefore wish to turn to the most salient change in the structure of international asset positions, which has been in gross rather than in net positions.

To obtain a detailed time profile of the decrease in home bias we now let $\lambda$ vary from period to period. We do so in two ways: first, by running a sequence of cross-sectional versions of our level risk sharing regression:

$$
c_{k t}-c_{t}^{*}=\left(1-\lambda_{t}\right)\left[y_{t}^{k}-y_{t}^{*}\right]+\tau_{t}+u_{k t}
$$


Secondly, in order to capture the impact of increased gross-asset holdings over time, we modify our panel level risk sharing regression to take account of the internationalisation of average gross asset positions. Specifically, we parametrize $\lambda$ as

$$
\left(1-\lambda_{t}^{G F A}\right)=\kappa_{0}+\kappa_{1} G F A_{t}
$$

where $G F A_{t}$ is the average (across countries) gross foreign asset position relative to GDP:

$$
\overline{G F A}_{t}=\frac{1}{K} \sum_{k=1}^{K} G F A_{t}^{k} \text { and } G F A_{t}^{k}=\frac{A_{t}^{k}+L_{t}^{k}}{Y_{t}^{k}}
$$

Here, $K$ denotes the number of countries, $A_{t}^{k}$ is assets and $L_{t}^{k}$ liabilities and the bar denotes the cross-sectional mean. Our data source is the March 2006 release of the external wealth of nations data set by Philip Lane and Gianmaria Milesi-Ferretti (2006). To obtain estimates of $\kappa_{0}$ and $\kappa_{1}$, we plug (14) into our panel level risk sharing regression and estimate the ensuing regression with interaction terms by panel dynamic OLS. Based on these estimates, we can then obtain a second time series of $1-\lambda_{t}$ from (14). We refer to this alternative estimate of $\lambda$ as $\lambda^{G F A}$.

We obtain these two time-varying measures of $\lambda$ for the period from 1975 to 2004. Using panel dynamic OLS, we estimate

$$
\left(1-\lambda_{t}^{G F A}\right)=1.01-0.1 \overline{G F A}_{t}
$$

with PDOSL-corrected $t$-statistics on $\kappa_{0}$ and $\kappa_{1}$ of 19.97 and 2.94 respectively. There is a statistically significant link betweeen average gross foreign asset positions and risk sharing. Our estimate of $\kappa_{0}$ is virtually unity, suggesting that cross-holdings of assets seem to account for all the consumption risk sharing we see in the data. Finally, it is interesting to appreciate the magnitude of the coefficient $\kappa_{1}$ : increasing average gross foreign asset holdings by 100 percent of $G D P$ will increase consumption risk sharing by roundabout 10 percentage points.

In Figure (1) we plot both the estimated coefficients $\left(1-\lambda_{t}\right)$ from the sequence of cross-sectional regressions in (13) as well as the measure based on the parametrization (14), $1-\lambda_{t}^{G F A}$. Though obtained from different approaches, the two measures both clearly indicate an increase in risk sharing that is of a very similar magnitude. We obtain standard errors for $1-\lambda_{t}$ from a jackknife procedure (Efron (1982)), in which we re-estimate the sequence $1-\lambda_{t} 23$ times, dropping one country from the sample at a time. Over most of the sample period, the $G F A$-based measure is statistically indistinguishable 
from $1-\lambda_{t}{ }^{13}$ We find this particularly remarkable since we have not been using any information about asset holdings in estimating the sequence of cross-sectional regressions (13). ${ }^{14}$ These findings suggest that the decline in our home bias measure and the associated rise in risk sharing are indeed intimately linked to the growth in international asset portfolio diversification.

\section{Summary and Conclusion}

A key finding of our paper is that consumption risk sharing among OECD countries has improved dramatically over the last decade. This finding is what one should expect in a world where the barriers to international capital flows have virtually been removed and it ties in with the bulk of empirical evidence that suggests that international cross-holdings of claims to capital have grown considerably. Still, the literature so far has found it relatively difficult to document that higher capital mobility actually does find its reflection in better international consumption risk sharing. Our framework, based on non-stationary panel regressions, has allowed us to document that countries' consumption risks are indeed a lot more diversified now than they were in the past. Improvements in risk sharing, however, seem to be a longerterm phenomenon. This is why they are more easily revealed by our level risk sharing regressions and not by econometric specifications that emphasize the business cycle link between consumption and output risk by using data that has been differenced to induce stationarity.

Not only do our estimates suggest that international consumption risk sharing has increased considerably during the recent globalization period. They also reveal a marked increase in the role of international income flows for risk sharing among countries and this increase seems to be tightly linked to the internationalisation of industrialised countries' investment positions.

\footnotetext{
${ }^{13}$ Only towards the end of the sample period, the two measures diverge somewhat, as the decline in $1-\lambda_{t}$ seems to flatten for a couple of years. A potential explanation is that the global stock market decline after 2000 has lowered the value of equity and other financial assets relative to real assets, notably human wealth and housing. Since holdings of these assets are not internationally diversified, international risk sharing may well have decreased temporarily only to pick up again in 2003 with the recovery of international stock markets. Since $1-\lambda_{t}^{G F A}$ is a function of gross foreign asset positions only - which have continued to grow relative to GDP - it does not detect this temporary decrease in risk sharing.

${ }^{14}$ In fact, this is a major advantage of our levels-based regression approach. Sequences of cross-sectional regressions of differenced risk sharing regressions are much more volatile and only show a statistically significant link to measures of financial portfolio diversification once they have been filtered. See e.g. Sørensen et al. (2006) and Kose et al. (2006).
} 
Again, the increase in capital income flows is much more pronounced once we focus on the longer-term interactions between the data and at these horizons our empirical model - that is estimated from output and consumption data alone - can replicate this rise in international investment income flows with remarkable precision.

A number of influential recent studies, notably Lane and Milesi-Ferretti (2003, 2005) and Rey and Gourinchas (2006) have emphasized the role of valuation effects for the dynamics of international asset positions. At business cycle horizons, such valuation effects could by themselves be an important channel of risk sharing that allows to substitute for capital income flows. In ongoing work, we explore the possibility that this could help explain why the rise of income flows derived from international investment positions is much more obvious in the longer-term while such capital income flows remain relatively limited at shorter horizons.

\section{References}

[1] Artis, Michael J. and Mathias Hoffmann (2004). 'Financial Globalization, International Business Cycles and Consumption Risk Sharing' (October 2004). CEPR Discussion Paper No. 4697. http://ssrn.com/abstract=639202.

[2] Asdrubali, P., Sørensen, P. E. and Yosha, O. (1996). 'Channels of interstate risk sharing: United States 1963-90.' Quarterly Journal of Economics, vol. 111, pp.1081-1110.

[3] Backus, D., Kehoe, P. and Kydland, F. (1992), 'International Real Business Cycles', Journal of Political Economy 100(4): 745-775.

[4] Baxter, M. and Crucini, M. J. (1995), 'Business Cycles and the Asset Structure of Foreign Trade', International Economic Review 36(4):821853.

[5] Becker, S. O. and Hoffmann, M. (2006). 'Intra- and International RiskSharing in the Short Run and the Long Run', European Economic Review, vol. 50, pp.777-806.

[6] Cochrane, J. H. (1991) 'A simple test of consumption insurance', Journal of Political Economy, vol. 99(5), pp. 957-976.

[7] Crucini, M. (1999). 'On international and national dimensions of risk sharing', The Review of Economics and Statistics, February 1999, 81(1): 73-84. 
[8] DelNegro, M. (2002). 'Asymmetric shocks among U.S. states', Journal of International Economics 56 (2002), pp. 273-297.

[9] Efron, B. (1982). The Jackknife, the Bootstrap and Other Resampling Plans. CBMS-NSF Regional Conference Series in Applied Mathematics, Monograph 38, SIAM, Philadelphia.

[10] Gourinchas, Pierre-Olivier and Hélène Rey (2006). 'International Financial Adjustment', mimeo, Princeton University.

[11] Heathcote, Jonathan and Fabrizio Perri (2004). 'Financial Globalization and Real Regionalization', Journal of Economic Theory.

[12] Hess, G.D. and Shin, K. (1998). 'Intranational Business Cycles in the United States', Journal of International Economics, 44, pp. 289-313.

[13] Heston, A., Summers, R. and Aten, B. (2006) Penn World Table Version 6.2, Center for International Comparisons at the University of Pennsylvania (CICUP), September 2006.

[14] Imbs, Jean (2006). 'The real effects of financial integration', Journal of International Economics, vol 68, 296-324.

[15] Kose, Ayhan, Prasad, Eswar S. and Marco E. Terrones (2006). 'How does financial globalization affect risk sharing: patterns and channels', paper presented at the 7th Jacques Polak Annual Research Conference hosted by the IMF, Nov. 9-10 2006.

[16] Kraay, A., Loayza, N., Serven L. and J. Ventura (2000). 'Country Portfolios', NBER Working Paper \#7795.

[17] Lane, P. D. (2000). 'International Investment Positions: A CrossSectional Analysis' Journal of International Money and Finance, 19(4), 513-534.

[18] Lane, P. D. (2001). 'Do International Investment Income Flows Smooth Income?', Weltwirtschaftliches Archiv 137(4), 714-736.

[19] Lane, P. D. and G. M. Milesi-Ferretti (2001). 'The External Wealth of Nations: Measures of Foreign Assets and Liabilities for Industrial and Developing Nations', Journal of International Economics 55, 263-294.

[20] Lane, P. D. and G. M. Milesi-Ferretti (2003). 'International Financial Integration', International Monetary Fund Staff Papers, 50(S), 82-113. 
[21] Lane, P. D. and G. M. Milesi-Ferretti (2005). 'A Global Perspective on External Positions.' NBER Working Paper No. 11589 forthcoming in Clarida, Richard H. (editor), G7 Current Account Imbalances: Sustainability and Adjustment. National Bureau of Economic Research Conference Report. The University of Chicago Press.

[22] Lane, P. D. and G. M. Milesi-Ferretti (2006). 'The External Wealth of Nations Mark II: Revised and Extended Estimates of Foreign Assets and Liabilities, 1970-2004', International Monetary Fund Working Paper No. $06 / 69$.

[23] Lewis, K. (1999). 'Trying to Explain Home Bias in Equities and Consumption.' Journal of Economic Literature, 37(2), 571-608.

[24] Mace, B. (1991) 'Full Insurance in the Presence of Aggregate Uncertainty', Journal of Political Economy, vol. 99(5), pp. 928-956.

[25] Mark, N. C. and D. Sul (2003). "Cointegration Vector Estimation by Panel DOLS and Long-Run Money Demand," Oxford Bulletin of Economics and Statistics, 65, 665-680.

[26] Obstfeld, Maurice (2004). 'External adjustment.' NBER working paper 10843.

[27] Pedroni, Peter (2004).'Panel Cointegration; Asymptotic and Finite Sample Properties of Pooled Time Series Tests with an Application to the Purchasing Power Parity Hypothesis,' Econometric Theory, 20, 597-325.

[28] Phillips, P. C. B. and Moon, H. R. (1999) 'Linear Regression Limit Theory for Nonstationary Panel Data', Econometrica 67 (5), 1057-1111.

[29] Sørensen, B. E. and Yosha, O. (1998). 'International risk sharing and European Monetary Unification.' Journal of International Economics, vol. 45 , pp. 211-38.

[30] Sørensen, B. E. and Yosha, O., Wu, Y.-T. and Zu Y. (2006). 'Home Bias and International Risk Sharing: Twin Puzzles Separated at Birth', manuscript, University of Houston.

[31] Shiller, R. J. (1993). Macro Markets: creating institutions for managing society's largest economic risk. Clarendon Lectures in Economics Series, Oxford University Press.

[32] Townsend, R. M. (1994). 'Risk and Insurance in Village India', Econometrica, 62( 3), 539-591. 
Table 1: Estimates of the home bias $(1-\lambda)$

Panel I: Pooled Regressions (w/o fixed effects)

$$
\left(c_{t}^{k}-c_{t}^{*}\right)=\text { const }+\tau_{t}+(1-\lambda)\left(y_{t}^{k}-y_{t}^{*}\right)+u_{t}^{k}
$$

United States

OECD

(1960-90)

OLS

$0.48 \quad(0.01)$

$0.47 \quad(0.02)$

1960-90 1990-2004

$0.93 \quad(0.01)$

$0.75 \quad(0.03)$

$0.74 \quad(0.06)$

\section{Panel II: Fixed effect regressions}

$$
\left(c_{t}^{k}-c_{t}^{*}\right)=\text { const }+\tau_{t}+\phi^{k}+\beta_{U}\left(y_{t}^{k}-y_{t}^{*}\right)+u_{t}^{k}
$$

United States

(1960-90)
OECD

1960-90
1990-2004
OLS
$0.50 \quad(0.02)$
$0.98 \quad(0.02)$
$0.63 \quad(0.02)$

Panel Dynamic OLS $0.52 \quad(0.04)$

$0.99 \quad(0.04)$

$0.66 \quad(0.03)$

Cointegration tests

$-2.36 \quad-2.42$

$-2.17$

NOTES: The results reported for the panel dynamic OLS estimation are based on estimating equations of the form $c_{k t}-c_{k t}^{*}=\widehat{b} x_{k t}+\sum_{l=-p}^{p} \delta_{k l} \Delta x_{t-l}+v_{k t}$ where $x_{k t}=\left(y_{k t}-y_{k t}^{*}\right)$ and $v_{t}^{k}=\tau_{t}+u_{t}^{k}$ or $v_{t}^{k}=\tau_{t}+\phi_{k}+u_{t}^{k}$, depending on whether it is a pooled or fixed regression. Standard errors are given in parentheses. Those for the PDOLS estimates are based on Mark and Sul (2003).All regressions control for time fixed effects. The panel cointegration tests at the bottom of the table are Pedroni's (20004) group mean t-statistics and are based on the PDOLS fixed-effect regressions. 
Table 2: Risk sharing patterns based on predicted and actual income data

\begin{tabular}{|c|c|c|c|c|c|c|}
\hline \multirow[b]{3}{*}{ Data } & \multicolumn{2}{|c|}{ United States } & \multicolumn{4}{|c|}{ OECD } \\
\hline & \multicolumn{2}{|c|}{$1-\lambda=0.48$} & \multicolumn{2}{|c|}{$\begin{array}{r}1970-90 \\
1-\lambda=0.90\end{array}$} & \multicolumn{2}{|c|}{$\begin{aligned} & 1990-2004 \\
& 1-\lambda= 0.74\end{aligned}$} \\
\hline & ex ante & ex post & ex ante & ex post & ex ante & ex post \\
\hline & \multicolumn{4}{|c|}{ Levels Regressions } & & \\
\hline predicted & $\begin{array}{l}0.45 \\
(0.01)\end{array}$ & $\begin{array}{l}0.03 \\
(0.04)\end{array}$ & $\begin{array}{l}0.08 \\
(0.01)\end{array}$ & $\begin{array}{l}-0.01 \\
(0.06)\end{array}$ & $\begin{array}{l}0.29 \\
(0.01)\end{array}$ & $\begin{array}{l}0.06 \\
(0.03)\end{array}$ \\
\hline \multirow[t]{2}{*}{ actual } & $\begin{array}{l}0.45 \\
(0.03)\end{array}$ & $\begin{array}{l}0.03 \\
(0.03)\end{array}$ & $\begin{array}{l}0.01 \\
(0.05)\end{array}$ & $\begin{array}{l}0.06 \\
(0.06)\end{array}$ & $\begin{array}{l}0.26 \\
(0.04)\end{array}$ & $\begin{array}{l}0.09 \\
(0.04)\end{array}$ \\
\hline & \multicolumn{4}{|c|}{ Differenced Regressions } & & \\
\hline predicted & $\begin{array}{l}0.47 \\
(0.01)\end{array}$ & $\begin{array}{l}0.37 \\
(0.03)\end{array}$ & $\begin{array}{l}0.08 \\
(0.001)\end{array}$ & $\begin{array}{l}0.18 \\
(0.04)\end{array}$ & $\begin{array}{l}0.28 \\
(0.01)\end{array}$ & $\begin{array}{l}0.05 \\
(0.04)\end{array}$ \\
\hline \multirow[t]{3}{*}{ actual } & $\begin{array}{l}0.39 \\
(0.01)\end{array}$ & $\begin{array}{l}0.46 \\
(0.03)\end{array}$ & $\begin{array}{l}0.03 \\
(0.02)\end{array}$ & $\begin{array}{l}0.24 \\
(0.04)\end{array}$ & $\begin{array}{l}0.06 \\
(0.03)\end{array}$ & $\begin{array}{l}0.27 \\
(0.05)\end{array}$ \\
\hline & \multicolumn{4}{|c|}{ Correlations } & & \\
\hline & \multicolumn{2}{|c|}{0.77} & \multicolumn{2}{|c|}{0.94} & & 0.85 \\
\hline
\end{tabular}

NOTES: regression coefficients from equations (10) (ex ante) and (11) (ex post), based on actual and predicted income data. The predicted income data are generated according to equation (2) with the portfolio shares $\lambda$ given at the top of the column. All regressions control for time-specific and region- or country specific fixed effects. Under the heading 'correlations' we report the average across countries or regions of the correlation between predicted and actual idiosyncratic income growth. 
Figure 1: The increase in consumption risk sharing 1975-2004.

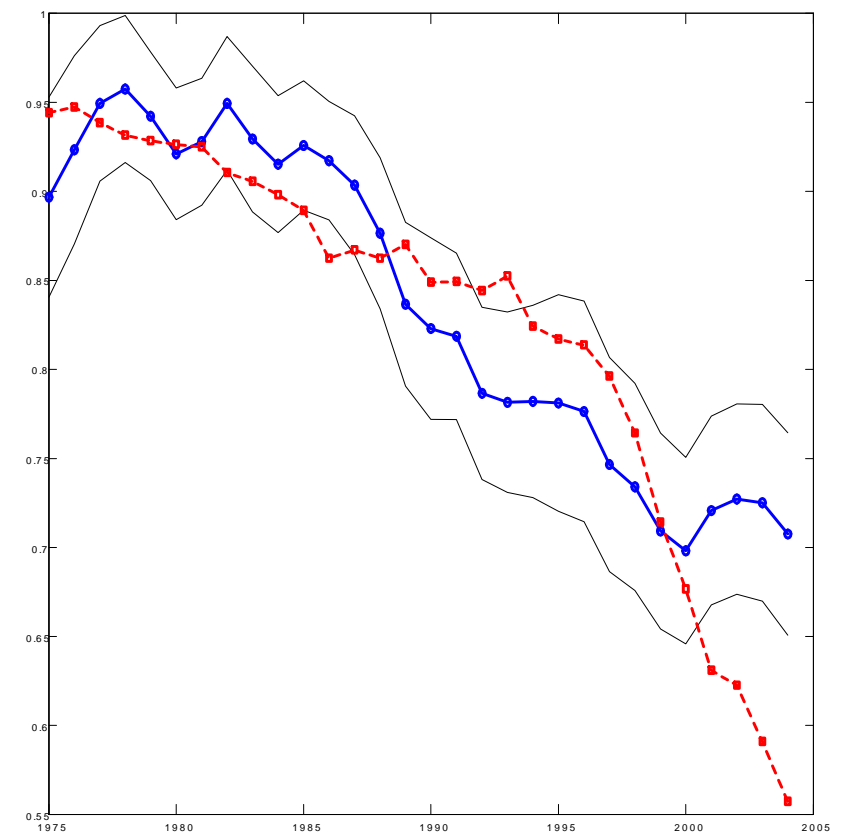

Notes: The blue (solid /dots) line is the sequence of cross-sectional estimates of $\left(1-\lambda_{t}\right)$. The red (dashed/ squares) line is $1-\lambda_{t}^{G F A}=1.01-0.1 \overline{G F A}_{t}$ where $\overline{G F A}_{t}$ is the cross-country mean gross foreign asset position. The thin (black) solid lines are the plus/minus two standard deviation bands for $1-\lambda_{t}$. These standard deviations are obtained using a jackknife resampling procedure. 